\title{
The Effect of Advance Care Planning on Heart Failure: a Systematic Review and Meta-analysis
}

\author{
Markus Schichtel, DPhil ${ }^{\top}\left(\mathbb{D}\right.$, Bee Wee, PhD², Rafael Perera, DPhil ${ }^{3}$, and Igho Onakpoya, \\ DPhil
}

'Department of Public Health and Primary Care, Primary Care Unit, University of Cambridge, Cambridge, UK; ${ }^{2}$ Oxford Centre for Education and Research in Palliative Care, Churchill Hospital, Oxford, UK; ${ }^{3}$ Nuffield Department of Primary Care Health Sciences, University of Oxford, Oxford, UK.

BACKGROUND: Advance care planning is widely advocated to improve outcomes in end-of-life care for patients suffering from heart failure. But until now, there has been no systematic evaluation of the impact of advance care planning (ACP) on clinical outcomes. Our aim was to determine the effect of ACP in heart failure through a meta-analysis of randomized controlled trials (RCTs).

METHODS: We searched CINAHL, Cochrane Central Register of Controlled Trials, Database of Systematic Reviews, Embase, ERIC, Ovid MEDLINE, Science Citation Index and PsycINFO (inception to July 2018). We selected RCTs including adult patients with heart failure treated in a hospital, hospice or community setting. Three reviewers independently screened studies, extracted data, assessed the risk of bias (Cochrane risk of bias tool) and evaluated the quality of evidence (GRADE tool) and analysed interventions according to the Template for Intervention Description and Replication (TIDieR). We calculated standardized mean differences (SMD) in random effects models for pooled effects using the generic inverse variance method.

RESULTS: Fourteen RCTs including 2924 participants met all of the inclusion criteria. There was a moderate effect in favour of ACP for quality of life (SMD, 0.38; 95\% CI [0.09 to 0.68]), patients' satisfaction with end-of-life care (SMD, 0.39; 95\% CI [0.14 to 0.64]) and the quality of end-of-life communication (SMD, 0.29; 95\% CI [0.17 to 0.42]) for patients suffering from heart failure. ACP seemed most effective if it was introduced at significant milestones in a patient's disease trajectory, included family members, involved follow-up appointments and considered ethnic preferences. Several sensitivity analyses confirmed the statistically significant direction of effect. Heterogeneity was mainly due to different study settings, length of follow-up periods and compositions of ACP.

CONCLUSIONS: ACP improved quality of life, patient satisfaction with end-of-life care and the quality of end-of-life communication for patients suffering from heart failure and could be most effective when the right timing, followup and involvement of important others was considered.

KEY WORDS: heart failure; palliative care; advance care planning; effect; outcomes; systematic review; meta-analysis.

Received July 15, 2019

Revised September 16, 2019

Accepted October 11, 2019

Published online November 12, 2019
J Gen Intern Med 35(3):874-84

DOI: $10.1007 / \mathrm{s} 11606-019-05482-w$

(C) The Author(s) 2019. This article is an open access publication

\section{BACKGROUND}

Regardless of therapeutic advances, heart failure remains an unpredictable, progressive and ultimately fatal long-term condition. ${ }^{1,2}$ Existing therapies delay, but generally tend not to reverse disease progression. ${ }^{3}$ Consequently, the prevalence of symptomatic heart failure has increased, including a prolongation of the refractory phase of the disease. ${ }^{4}$ An ageing population, a rising prevalence and new life-prolonging treatment approaches mean that over $5 \%$ of patients suffering from heart failure have developed treatment refractory symptoms. ${ }^{5}$ There is widespread recognition that these patients merit support from specialist supportive and palliative care services. ${ }^{6-10}$

Advance care planning (ACP) is widely advocated to improve quality of life and patient satisfaction with end-of-life care in heart failure and a reduction of stress and depression in surviving relatives. $5,7,11,12 \mathrm{ACP}$ is defined as a voluntary process of discussion between healthcare professionals, patients, family and important others to identify patient's preferences if the patient may lack the competence to make such decisions in the future. ${ }^{13,14} \mathrm{ACP}$ can be a chance for patients to describe what they want to happen and what they do not want to happen in the future. For example, ACP supports patients by clarifying their resuscitation preferences in case of a cardiac arrest, whether or not or under what circumstances to disable an implantable cardioverter-defibrillator (ICD), choosing a healthcare proxy, deciding on their preferred place of care or making decisions on artificial hydration. ${ }^{13}$ ACP can take the shape of a structured discussion or result in the documentation of care preferences in medical records that are regularly reviewed and updated. The context of ACP can be a nurse or consultant-led heart failure outpatient clinic, during inpatient care, or in the course of an appointment with a primary care clinician.

While the use of ACP is promoted to provide better clinical outcomes, its effectiveness to achieve that aim has not been systematically assessed. ${ }^{15}$ The majority of systematic reviews on ACP are concerned with the effect of interventions that promote the implementation of ACP and assess outcomes like the rate of $\mathrm{ACP}$ conversations or the completion of $\mathrm{ACP}$ 
documents. ${ }^{16-21}$ The systematic literature reviews that investigate the impact of ACP on end-of-life care outcomes combine qualitative and quantitative studies, do not conduct a meta-analysis and do not focus on the effect of ACP on heart failure. ${ }^{22-27}$ The aim of this study was to undertake a systematic review and meta-analysis of RCTs to determine whether end-of-life care which included ACP resulted in improved outcomes for patients suffering from heart failure compared to end-of-life care which did not incorporate ACP. Our hypothesis was that ACP improved clinical outcomes for patients suffering from heart failure. Our main research question was "What is the effect of ACP on clinical outcomes for patients suffering from heart failure?"

The objectives were as follows:

- To determine the effect of advance care planning on the quality of life of patients suffering from heart failure, their satisfaction with end-of-life care through random effects meta-analyses

- To conduct sensitivity analyses and investigate causes of clinical heterogeneity

- To explore characteristics of advance care planning interventions that are associated with high and low effect sizes

\section{METHODS}

We conducted this review in accordance with the Preferred Reporting Items for systematic reviews and meta-analysis (PRISMA-P) ${ }^{28}$ the Cochrane Collaboration reporting items for systematic reviews and meta-analysis ${ }^{29}$ and the Grading of Recommendation Assessment, Development, and Evaluation (GRADE) for the quality of evidence in selected trials. ${ }^{30}$ Intervention impact was reported based on CONSORT guidelines. ${ }^{31}$ Additional File (AF) 1 shows the review protocol.

\section{Study Selection}

We included only randomized controlled trials (RCTs) and cluster randomized controlled trials (cRCTs). No restrictions were placed on the healthcare setting, context or healthcare professional involved. Patients were eligible if they suffered from heart failure defined as a complex syndrome in which the ability of the heart to maintain the circulation of blood is impaired as a result of a structural or functional impairment of ventricular filling or ejection. ${ }^{5}$ Symptoms were classified according to severity using the New York Heart Association (NYHA) functional classification as found in medical records or by a clinician's diagnosis. ${ }^{32}$ Patients were seen in primary or secondary care, living in the community or nursing homes. We did exclude studies involving people under the age of 18 years and suffering from congenital heart disease. ${ }^{33}$

As defined in policy documents and by experts, we included all types of ACP interventions that provided a coordinated and comprehensive approach of care for patients early, during or towards the end of suffering from heart failure. ${ }^{33-35}$ Authors had to state explicitly ACP intentions or this had to be evident in the composition of the intervention of the study. Interventions that only dealt with do-not-attempt cardio-pulmonaryresuscitation were excluded from the study because they on their own did not represent the complexity of ACP. ${ }^{36}$

We followed the recommendation of the European Association for Palliative Care for the selection of outcome measures ${ }^{37}$ including patient-reported outcome measures that had been validated with heart failure patients requiring palliative care. ${ }^{38}$ Therefore, we selected a priori as our primary outcome quality of life. As secondary outcomes, we chose patient satisfaction with end-of-life care and the quality of end-oflife communication between clinician and patient. Outcomes had to be measured through instruments that had psychometric properties.

\section{Data Sources and Searches}

Together with a specialist health science librarian (NR), we used filters to reliably identify RCTs and searched the following data bases from their inception until 13 July 2018: CINAHL, Cochrane Central Register of Controlled Trials, Cochrane Database of Systematic Reviews, Database of Abstracts of Reviews of Effects, Embase, ERIC, Ovid MEDLINE (SP), Other Non-Indexed Citations and Ovid MEDLINE(R), Science Citation Index, Social Science Citation Index \& Conference Proceedings and PsycINFO. A MEDLINE search strategy is presented in AF 2. We checked the reference lists of 11 relevant reviews ${ }^{16-25,39}$ and all potential cross references. We contacted authors of main trials and experts in the field who were known to conduct research for additional papers or to provide missing or unpublished study data.

\section{Data Extraction and Quality Assessment}

Titles and abstracts were independently screened against inclusion criteria by two reviewers (MS, IO). Disagreements were resolved by discussion or referred for arbitration to a third reviewer (RP). Full texts of screened papers were assessed for inclusion criteria and study quality. We pilot tested eligibility criteria and included a flow diagram of study selection and reasons for exclusion to conform to the PRIMSA statement.

We assessed the overall quality of the trials' methods by using the GRADE system Version 3.6.1. ${ }^{40}$ A GRADE profile was created for each pooled estimate, for each outcome and for single trials comparing ACP with standard care for each endof-life outcome. Two authors (MS, IO) independently extracted data from papers and documented findings. AF 3 gives an example of a data extraction form.

\section{Data Synthesis and Analysis}

We performed quantitative meta-analysis with RevMan 5.3.5 $5^{41}$ using random effects models. For individual studies with 
continuous outcomes measured by a variety of scale instruments, we calculated standardized mean differences (SMDs) with $95 \%$ confidence intervals (CI) between the intervention and control group as recommend by Cochrane. ${ }^{29}$ The effect of SMDs was interpreted as follows: $<0.2=$ small effect; between 0.2 and 0.5 moderate effect; 0.5 or higher $=$ large effect. ${ }^{29} \mathrm{We}$ re-expressed SMDs to odds ratios $\left[\log (\mathrm{OR})=\mathrm{SMD} \times \mathrm{pi} / \mathrm{sqrt}^{3}\right]$ to aid clinical interpretation as recommended by the Cochrane Handbook. ${ }^{29}$ We did not adjust sample sizes to account for clustering in the included $\mathrm{cRCT}^{42}$ as this study reported adjusted effect estimates, which took the intra-class coefficient found into consideration. We used a generic inverse variance approach and random effects meta-analysis to include the estimate into the meta-analysis. When multiple time points were reported, we used the one closest to 3 months post-intervention based on research practice in palliative care ${ }^{43}$ and the premise that it would require a reasonable length of time for ACP to take effect.

We assessed heterogeneity using the $I^{2}$ statistic stating the percentage of variability in effect estimates that is due to heterogeneity rather than to chance. ${ }^{44}$ Thresholds for the interpretation of heterogeneity were based on Cochrane guidance ${ }^{29}$ as follows: $0 \%=$ no heterogeneity; $>0$ to $40 \%$ : might not be important; 30 to 60\%: moderate heterogeneity; 50 to $90 \%$ : substantial heterogeneity; 75 to $100 \%$ : considerable heterogeneity. We investigated clinical heterogeneity by pre-specified subgroup analyses for each outcome stratified for patient population, length of followup periods and study setting. We compared interventions that included only ACP and interventions that included ACP as part of a palliative care programme. We analysed the characteristics of ACP interventions that resulted in either high or low effect sizes for each outcome and explored their content, timing and frequency and context of the intervention according to the Template for Intervention Description and Replication (TIDieR). ${ }^{45}$

We assessed publication bias by investigating the funnel plot symmetry and performing Egger's test ${ }^{46}$ with STATA version $14 .^{47}$ Two reviewers (MS, IO) independently assessed the risk of bias using the Cochrane Collaboration's tool for risk of bias domains. ${ }^{48}$

\section{RESULTS}

Of 9130 articles screened, we reviewed the full text of 85 studies. Fourteen studies (13 RCTs, one cRCTs) met all of the inclusion criteria for the quantitative analysis. Figure 1 shows the PRISMA flow diagram. A detailed description of each trial is provided in Table 1 . We included 14 studies in the metaanalysis involving 2924 unique participants. We excluded 71 studies with reasons provided in AF 4 "Characteristics of Excluded Studies."

\section{Characteristics of Included Studies}

Ten of the 14 studies were conducted in the USA, one in the $\mathrm{UK}^{53}$, one in Australia, ${ }^{54}$ one in Sweden ${ }^{50}$ and one in Hong Kong. ${ }^{61}$ The median sample size was 209 people (range 27 to
517 participants). The median age of participants was 65.85 (age range $58.1-84.5$ years). $40.83 \%(n=1194)$ of the total study population were female.

A summary of a risk of bias table and a risk of bias ratings for each study and each trial arm is included in AF 5. Allocation concealment (selection bias) was unclear in seven studies as authors did not describe methods of concealment. Blinding of participants was not possible in seven trials because of the nature of the interventions. One study had a high risk of detection bias since outcome assessors were aware of the participants' allocation to the intervention group. ${ }^{56}$

\section{Effects of ACP on Outcomes for Heart Failure}

AF 6 shows the GRADE quality ratings for each outcome. The mean score for the overall quality of evidence across all studies was low to moderate. This was mainly due to the fact that many participants could not be blinded to the nature of the intervention introducing a high risk of performance bias.

\section{Meta-analysis on ACP and Quality of Life}

Quality of life (QOL) was determined in seven studies (724 patients) (Fig. 2). ACP was associated with a statistically significant improvement for QOL (SMD, 0.38; 95\% CI [0.09 to 0.66], $p<0.009)$. The median follow-up duration was 12 weeks. Egger's test did not show any evidence ( $p=$ 0.406 ) of a small study effect on publication bias (AF 7).

\section{Meta-analysis on ACP and Patient Satisfaction}

Patient satisfaction with end-of-life care was assessed in four studies (1290 patients). ACP was associated with (Fig. 3) a statistically significant effect (SMD, 0.39; $95 \%$ CI $[0.14$ to 0.64$] ; p=0.003)$. The median follow-up duration was 14.4 weeks. Egger's test did not show any evidence $(p=0.584)$ of a small study effect on publication bias (AF 7).

\section{Meta-analysis on ACP and Quality of End-of- Life Communication}

Four studies measured the effect of ACP on the quality of endof-life communication (995 patients). ACP was associated with statistically significant improvement (Fig. 4) for the quality of end-of-life communication (SMD, 0.29; 95\% CI [0.17 to 0.42$] ; p<0.001)$. The median follow-up duration was 7.25 weeks. Egger's test of the 4 RCTs did not show any evidence $(p=0.095)$ of a small study effect on publication bias (AF 7).

To aid the clinical interpretation of the results, we reexpressed estimated SMDs for all outcomes as odds ratios according to Cochrane guidelines (AF 8). ${ }^{29} \mathrm{ACP}$ improved the quality of life for heart failure patients by approximately $93 \%$, patient satisfaction with end-of-life care by about $96 \%$ and the quality of end-of-life communication by around $52 \%$. 


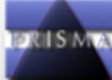

PRISMA 2009 Flow Diagram
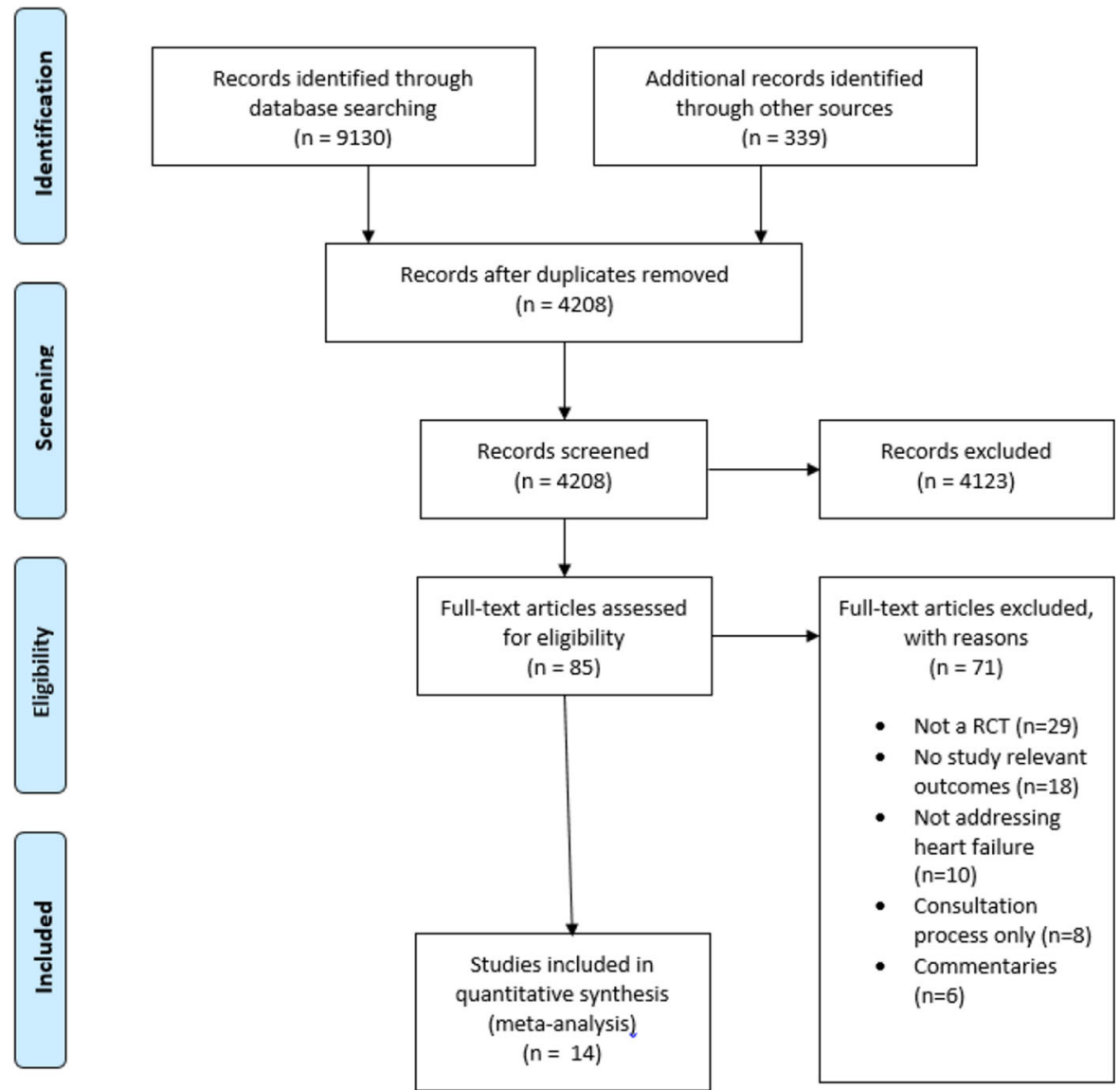

Figure 1 PRISMA flow diagram

\section{Characteristics of ACP Interventions with High and Low Effect Sizes}

Table 2 summarizes the characteristics of ACP interventions with the highest and lowest effect sizes by outcome. Generally, ACP interventions that included multiple components, educated patients, involved family members, offered follow-up and considered ethnic preferences were more effective than single component interventions that did not educate patients, did not involve family members and did not offer follow-up.

\section{Sensitivity Analyses and Heterogeneity}

Several sensitivity analyses (AF 9) including studies restricted to ACP only (SMD, $0.35 ; 95 \%$ CI $[-0.10$ to 0.81]) versus ACP plus palliative care programme (SMD, $0.32 ; 95 \%$ CI [0.16 to 0.48$]$ ), US-based studies (SMD, $0.37 ; 95 \%$ CI [ -0.05 to 0.79$]$ ) versus not US-based studies (SMD, 0.39; $95 \%$ CI [- 0.04 to 0.83$]$ ), and trials at low risk of bias (SMD, 0.34; $95 \%$ CI [0.03 to 0.65$]$ ) confirmed the consistency of the results of the primary analyses.
To investigate possible causes of heterogeneity, additional sensitivity analyses were performed by stratifying outcomes for patient populations, study settings and length of follow-up periods. No heterogeneity was detected for the hospital setting for quality of life, for the quality of end-of-life communication and for heart failure and other terminally ill patients for the outcome quality of end-of-life communication. Levels of heterogeneity seemed lower for shorter follow-up periods (1 to 4 weeks) than for longer follow-up durations (up to 12 or 24 weeks). Quality of life and patient satisfaction with end-of-life care showed higher levels of heterogeneity than quality of end-of-life communication. A summary of causes of heterogeneity for each outcome and subgroup is presented in Table 3. These differences are explored in more detail under the "Discussion" section.

\section{DISCUSSION}

\section{Principal Findings}

This literature review was the first systematic evaluation of the evidence base for the effect of ACP on end-of-life care outcomes 
Table 1 Summary of Included Studies

\begin{tabular}{|c|c|c|c|c|c|c|c|c|c|}
\hline $\begin{array}{l}\text { Study } \\
\text { (years) }\end{array}$ & Country & Setting & Speciality & $\begin{array}{l}\text { Description of } \\
\text { healthcare } \\
\text { professionals }\end{array}$ & $\begin{array}{l}\text { Description } \\
\text { of patients }\end{array}$ & $\begin{array}{l}\text { Patients } \\
\text { randomized/ } \\
\text { completed }\end{array}$ & $\begin{array}{l}\text { Female } \\
\text { patients } \\
\text { (no/\%)/ } \\
\text { mean } \\
\text { age } \\
\text { (years) }\end{array}$ & $\begin{array}{l}\text { Follow- } \\
\text { up } \\
\text { (weeks) }\end{array}$ & $\begin{array}{l}\text { Type(s) of } \\
\text { outcome(s) }\end{array}$ \\
\hline $\begin{array}{l}\text { Aiken }^{49} \\
(2006)\end{array}$ & USA & Community & $\begin{array}{l}\text { Palliative } \\
\text { Care }\end{array}$ & $\begin{array}{l}\text { Hospice nurse } \\
\text { and case } \\
\text { manager }\end{array}$ & $\begin{array}{l}\text { HF-NYHA } \\
\text { III, IV and } \\
\text { COPD }\end{array}$ & $192 / 191$ & $\begin{array}{l}123 / 64 \\
68.5\end{array}$ & 12 & QOL \\
\hline $\begin{array}{l}\mathrm{Au}^{42} \\
(2012)\end{array}$ & USA & Hospital & Medicine & $\begin{array}{l}\text { Internal and } \\
\text { pulmonary } \\
\text { physicians }\end{array}$ & $\begin{array}{l}\text { HF-NYHA } \\
\text { III, IV, } \\
\text { COPD, CRF }\end{array}$ & $376 / 306$ & $\begin{array}{l}149 / \\
53.26 \\
69.4\end{array}$ & 2 & QEOLC \\
\hline $\begin{array}{l}\text { Brannstrom }^{50} \\
(2014)\end{array}$ & Sweden & Hospital & Geriatrics & Geriatricians & $\begin{array}{l}\text { CHF, NYHA } \\
\text { III-IV }\end{array}$ & $72 / 61$ & $\begin{array}{l}21 / 29.1 \\
81.9\end{array}$ & 12 & QOL \\
\hline $\begin{array}{l}\text { Briggs } \\
(2004)\end{array}$ & USA & Hospital & Medicine & $\begin{array}{l}\text { Cardiologists, } \\
\text { renal } \\
\text { physicians }\end{array}$ & $\begin{array}{l}\text { HF-NYHA } \\
\text { II, III, IV and } \\
\text { CRF }\end{array}$ & $27 / 27$ & $\begin{array}{l}11 / 40.74 \\
68.7\end{array}$ & 1 & QEOLC \\
\hline $\begin{array}{l}\text { Brumley }^{52} \\
(2007)\end{array}$ & USA & Community & $\begin{array}{l}\text { Primary } \\
\text { and } \\
\text { Palliative } \\
\text { Care }\end{array}$ & $\begin{array}{l}\text { Primary care } \\
\text { and palliative } \\
\text { care clinicians }\end{array}$ & $\begin{array}{l}\text { HF-NYHA } \\
\text { III-IV, } \\
\text { COPD, } \\
\text { cancer }\end{array}$ & $310 / 297$ & $\begin{array}{l}146 / 49 \\
65.1\end{array}$ & 12 & PSEOLC \\
\hline $\begin{array}{l}\text { Denvir }^{53} \\
(2016)\end{array}$ & UK & Hospital & Cardiology & $\begin{array}{l}\text { Cardiology } \\
\text { staff }\end{array}$ & $\begin{array}{l}\text { Patients with } \\
\text { HF-NYHA } \\
\text { III, IV and } \\
\text { ACS }\end{array}$ & $50 / 44$ & $\begin{array}{l}20 / 40 \\
81.05\end{array}$ & 12 & QOL \\
\hline $\begin{array}{l}\text { Detering }{ }^{54} \\
(2010)\end{array}$ & Australia & Hospital & $\begin{array}{l}\text { Medicine } \\
\text { Cardiology }\end{array}$ & $\begin{array}{l}\text { Internal and } \\
\text { pulmonary } \\
\text { physicians, } \\
\text { cardiologists }\end{array}$ & $\begin{array}{l}\text { Elderly HF } \\
\text { patients }>80 \\
\text { years of age }\end{array}$ & $309 / 305$ & $\begin{array}{l}162 / 52.5 \\
84.5\end{array}$ & 12 & PSEOLC \\
\hline $\begin{array}{l}\text { Doorenbos }{ }^{55} \\
\text { (2016) }\end{array}$ & USA & Hospital & Cardiology & $\begin{array}{l}\text { Cardiology } \\
\text { staff }\end{array}$ & $\begin{array}{l}\text { HF-NYHA I, } \\
\text { II, III, IV }\end{array}$ & $80 / 73$ & $\begin{array}{l}19 / 23.7 \\
58.1\end{array}$ & 2 & QEOLC \\
\hline $\begin{array}{l}\text { Engelhardt }{ }^{56} \\
(2006)\end{array}$ & USA & $\begin{array}{l}\text { Hospital } \\
\text { and } \\
\text { community }\end{array}$ & $\begin{array}{l}\text { Primary } \\
\text { care and } \\
\text { medicine }\end{array}$ & $\begin{array}{l}\text { Primary and } \\
\text { secondary care } \\
\text { physicians }\end{array}$ & $\begin{array}{l}\text { HF-NYHA } \\
\text { III, IV, } \\
\text { COPD, } \\
\text { cancer }\end{array}$ & $275 / 186$ & $\begin{array}{l}118 / 82.6 \\
\text { Not } \\
\text { reported }\end{array}$ & 12 & PSEOLC \\
\hline $\begin{array}{l}\mathrm{Gade}^{57} \\
(2008)\end{array}$ & USA & Hospital & Medicine & $\begin{array}{l}\text { Internal } \\
\text { physicians }\end{array}$ & $\begin{array}{l}\text { HF, cancer, } \\
\text { COPD, } \\
\text { stroke, CRF }\end{array}$ & $517 / 512$ & $\begin{array}{l}162 / 59 \\
73.3\end{array}$ & 24 & PSEOLC \\
\hline $\begin{array}{l}\text { Hopp }^{58} \\
(2016)\end{array}$ & USA & Hospital & $\begin{array}{l}\text { Palliative } \\
\text { care }\end{array}$ & $\begin{array}{l}\text { Palliative care } \\
\text { clinician and } \\
\text { nurse } \\
\text { practitioner }\end{array}$ & CHF patients & $85 / 85$ & $\begin{array}{l}41 / 48.2 \\
68.1\end{array}$ & 12 & QOL \\
\hline $\begin{array}{l}\text { Rogers } \\
(2017)\end{array}$ & USA & Hospital & $\begin{array}{l}\text { Palliative } \\
\text { care } \\
\text { cardiology }\end{array}$ & $\begin{array}{l}\text { Palliative care } \\
\text { clinicians, } \\
\text { cardiologists }\end{array}$ & $\begin{array}{l}\text { Patients with } \\
\text { HF-NYHA } \\
\text { III, IV }\end{array}$ & $150 / 106$ & $\begin{array}{l}71 / 47.3 \\
71.9\end{array}$ & 12 & QOL \\
\hline $\begin{array}{l}\text { Sidebottom } \\
\text { (2015) }\end{array}$ & USA & Hospital & Cardiology & $\begin{array}{l}\text { Cardiology } \\
\text { staff }\end{array}$ & HF patients & $232 / 167$ & $\begin{array}{l}110 / 47.4 \\
73.4\end{array}$ & 12 & QOL \\
\hline $\begin{array}{l}\text { Wong } \\
\text { (2016) }\end{array}$ & $\begin{array}{l}\text { Hong } \\
\text { Kong }\end{array}$ & Hospital & $\begin{array}{l}\text { Palliative } \\
\text { care }\end{array}$ & $\begin{array}{l}\text { Palliative care } \\
\text { physicians and } \\
\text { nurses }\end{array}$ & $\begin{array}{l}\text { Patients with } \\
\text { HF-NYHA } \\
\text { III, IV }\end{array}$ & $84 / 84$ & $\begin{array}{l}41 / 48.8 \\
78.3\end{array}$ & 12 & QOL \\
\hline
\end{tabular}

ACS acute coronary syndrome, CHF congestive heart failure, COPD chronic obstructive pulmonary disease, CRF chronic renal failure, HF heart failure, NYHA New York Heart Association, PSEOLC patient satisfaction with end-of-life care, QEOLC quality of end-of-life communication, QOL quality of life

in heart failure. The results of the meta-analyses from 14 RCTs including 2924 participants indicated that ACP improved.

- Quality of life (SMD, 0.38; 95\% CI [0.09 to 0.66])

- Patient satisfaction with end-of-life care (SMD, 0.39; 95\% CI [0.14 to 0.64])

- Quality of end-of-life communication (SMD, 0.29; 95\% CI [0.17 to 0.42]) in heart failure compared to usual care

Several sensitivity and subgroup analyses confirmed the direction of the effect. ACP alone compared to ACP as part of a palliative care programme might be equivalent in its effectiveness. ACP that included not only patients but also family members, offered follow-up occasions and considered ethnic preferences was more effective than ACP that did not cover these criteria.

\section{Comparison with Other Reviews}

At the time of writing, this review was the first to have analysed the effect of ACP on outcomes in heart failure in a meta-analysis with a consideration of heterogeneity and characteristics of intervention effectiveness. Several reviews had investigated the effectiveness of interventions to implement ACP but did not investigate the impact of ACP on heart failure. ${ }^{17-21,23-26,36}$ Some of these reviews conflated an analysis of the impact of ACP on end-of-life outcomes with the effect of interventions to promote the implementation of $\mathrm{ACP} .{ }^{26}$ Data on the actual impact of ACP on end-of-life outcomes was only presented descriptively and missing for heart failure. $^{26,} 36$ 


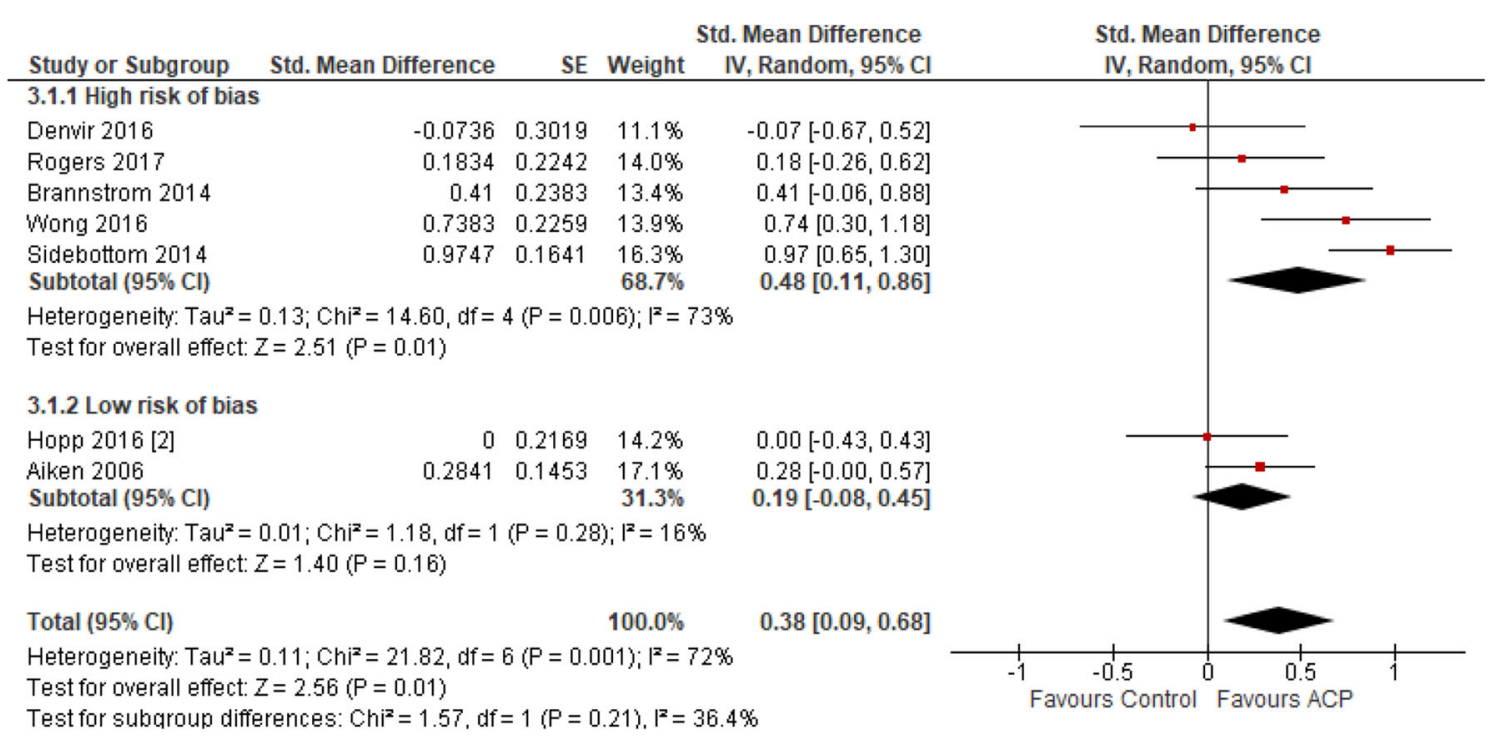

Figure 2 Effect of ACP on quality of life.

\section{Strengths and Limitations}

The strength of this review and meta-analyses consisted of the use of a robust search strategy, assessing the overall quality of the evidence with the GRADE system, rating risks of biases with the Cochrane risk of bias evaluation tool, statistically pooling data for each outcome, performing sensitivity analyses and exploring causes of heterogeneity and intervention effectiveness. Furthermore, we used random effects models and SMDs to account for variations in types of interventions and outcomes measures across studies.

The heterogeneity in studies was mainly due to different study populations combining heart failure patients with patients suffering from other life-limiting illnesses, different study settings, follow-up periods and a lack of standardization of using outcomes measures. The median age of participants was below the median age of people dying from heart failure in the general population. The median follow-up periods for clinical outcomes were comparatively short. It appears unclear whether the positive effect of ACP might mitigate over time. The majority of studies originated from the US but a sensitivity analysis comparing effect sizes of US-based studies with studies from other countries did not show a favourable effect dependent of the health care setting.

\section{Causes of Clinical Heterogeneity}

Heterogeneity is to be expected when aggregating evidence on the effect of complex interventions like ACP. ${ }^{62}$ ACP in itself tends to consist of multiple components and is implemented differently and in different settings. ${ }^{63}$ For example, the timing of offering ACP as an intervention in relation to the patient's

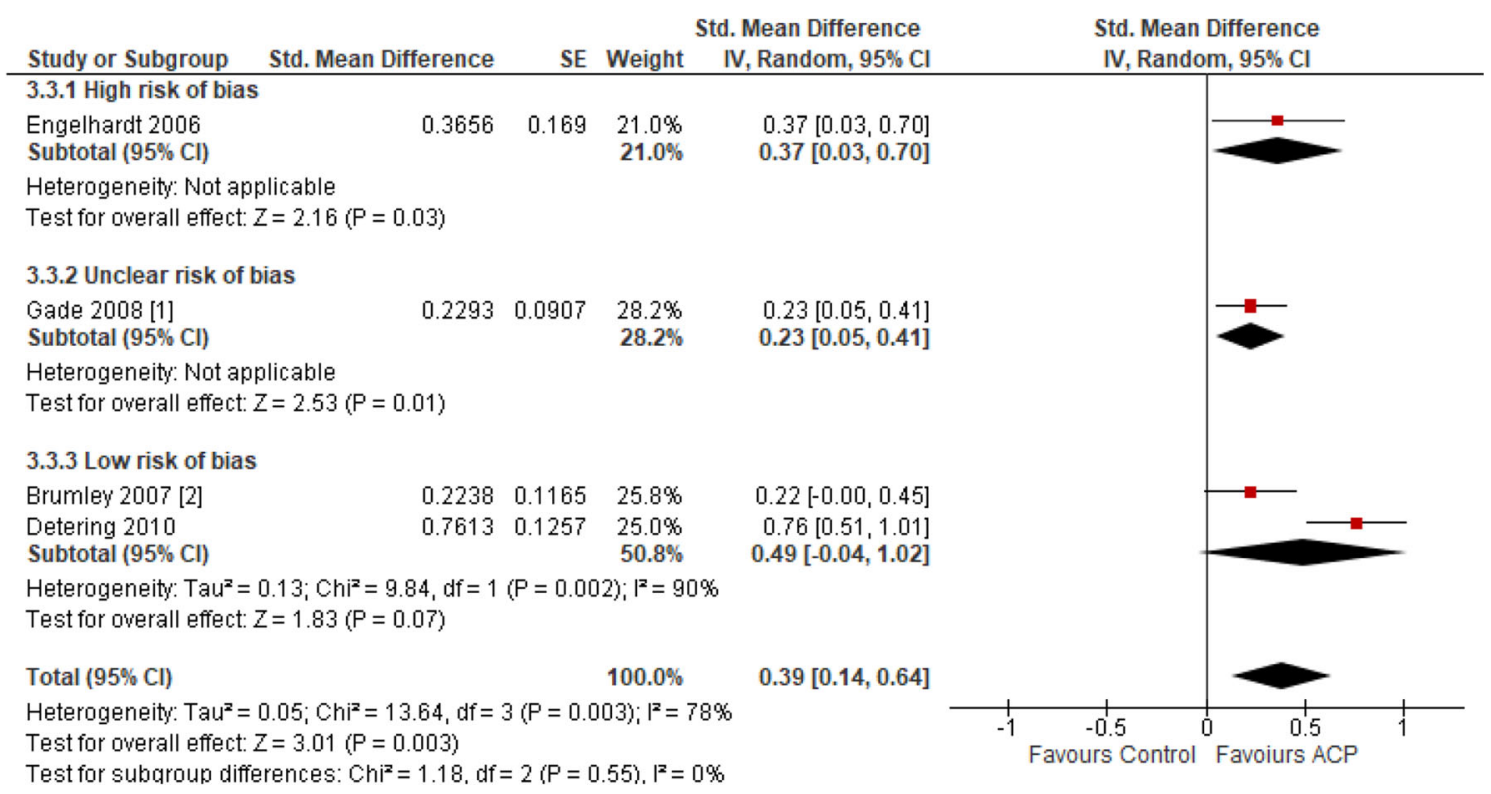

Figure 3 Effect of ACP on patient satisfaction. 


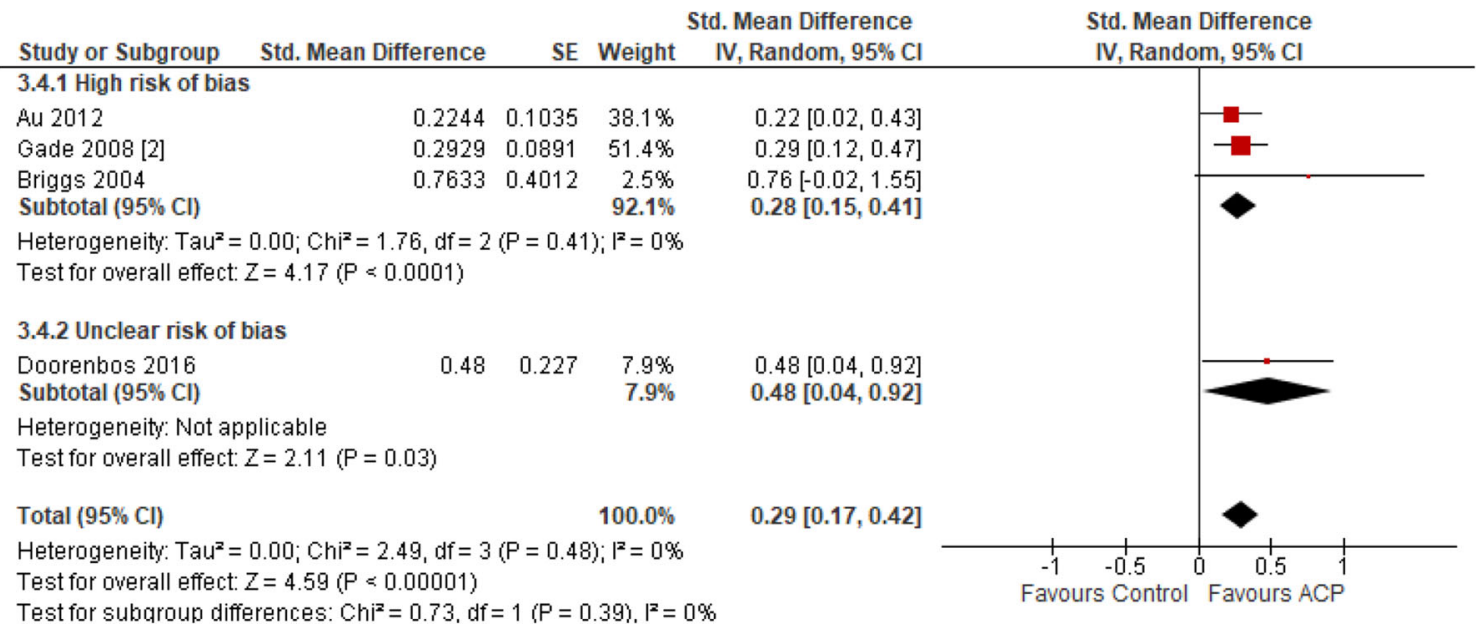

Figure 4 Effect of ACP on quality of communication.

disease trajectory varied in included studies. While most patients in the meta-analysis suffered from heart failure class III or IV of the New York Heart Association, ACP was initiated at different time points: during an admission to hospital, ${ }^{58}$ after a recent hospitalization, ${ }^{55}$ after a deterioration in the patient's health status ${ }^{52}$ or before a routine clinic appointment with a cardiologist. $^{53}$ These findings on the timing of ACP agree with the published literature which cites a change or deterioration in the patient's condition, a routine clinical review or a change in a patient's personal circumstances such as moving into a care home as possible triggers for ACP. ${ }^{13}$

Control patients tended to receive only usual medical practice but no ACP unless it was specifically requested. ${ }^{52,54,56}$ The majority of studies provided similar amounts of time for control patients, ${ }^{42,49-53,55,59,61}$ for example, through social calls consisting of conversational topics unrelated to clinical issues. Therefore, it seems likely that the ACP intervention and not just time made a difference to clinical outcomes. Two studies did not provide a clear description on whether an attempt was made to provide similar amounts of time with patients and the families of the control groups. ${ }^{57,58}$

\section{Characteristics of ACP interventions}

Our challenge was to constructively explore existing levels of heterogeneity and identify intervention components which may make the use of ACP more effective:

Sidebottom et al. ${ }^{60}$ attributed the success of their ACP intervention to using a trained ACP facilitators, educating patients in communicating their end-of-life care preferences, involving a family member and offering follow-up appointments. The literature affirmed the importance of using trained facilitators and designing multiple ACP components to improve patient outcomes. ${ }^{63-65}$ Similarly, Wong et al. ${ }^{61}$ thought that improvements in their QOL outcomes were due to a comprehensive palliative care programme including multiple ACP components: working as a multidisciplinary team, clear referral guidelines and involvement of carers and patients alike. Their approach is confirmed by the literature that indicates that ACP is more effective as a complex versus a single intervention. $^{15,65,66}$

By contrast, Hopp et al. ${ }^{58}$ used the design of a single component ACP intervention without any follow-up, involvement of family members or other healthcare professionals. Additionally, their trial population consisted mainly in African Americans. Studies have shown that this patient population prefers curative rather than palliative care approaches and is less likely to engage with ACP. ${ }^{67,68}$ A lack of consideration of ethnic preferences, missing follow-up and the exclusion of family members may well have contributed to the low effect of their ACP intervention. The low effect size for ACP in the study by Denvir et al. ${ }^{53}$ was mainly due to the study design, i.e. a feasibility RCT. The data generated in this small cohort was not intended to be sensitive or specific enough to observe a positive effect of the intervention for QOL. Additionally, a high mortality rate during the follow-up period further limited the utility of their data as a trial end point.

The study by Detering et al. ${ }^{54}$ cited five factors for improving patient satisfaction with end-of-life care ${ }^{1}$ : using trained facilitators, ${ }^{2}$ conducting a patient-centred discussion, ${ }^{3}$ the involvement of the family, ${ }^{4}$ correctly filing and communicating the ACP documentation with all parties, and ${ }^{5}$ a systematic education of doctors in communicating ACP. Likewise, the study by Engelhardt et al. ${ }^{56}$ delivered ACP through trained care coordinators who had an institutional identity and clinical credibility. Patients could schedule extra meetings with their care coordinator if they had further questions and follow-up was provided. The importance of using respected, senior clinicians to improve the uptake of an intervention like ACP is highlighted in the literature. ${ }^{69,70}$

Lower effect sizes for patient satisfaction with end-oflife care were found in the study by Brumley et al. ${ }^{52}$ While the intervention slightly improved outcomes, the authors thought that a major cause for the low effect size was the high mortality rate of the study population before follow-up. Their results suggested that providing 
Table 2 Characteristics of ACP Interventions

\begin{tabular}{|c|c|c|c|c|c|c|c|}
\hline$\overline{\text { Study }}$ & Outcome & $\begin{array}{l}\text { Effect size } \\
\text { SMD [95\% } \\
\text { CI] }\end{array}$ & ACP characteristics & ACP timing & $\begin{array}{l}\text { Education } \\
\text { of patient }\end{array}$ & $\begin{array}{l}\text { Involvement } \\
\text { of family }\end{array}$ & $\begin{array}{l}\text { ACP } \\
\text { follow- } \\
\text { up }\end{array}$ \\
\hline $\begin{array}{l}\text { Sidebottom } \\
(2014)\end{array}$ & QOL & $\begin{array}{l}0.94[0.62 \\
\text { to } 1.26]\end{array}$ & $\begin{array}{l}\text { A trained facilitator supports } \\
\text { patients to identify their care } \\
\text { preferences, completes an } \\
\text { ACP health directive and a } \\
\text { HF disease-specific care plan }\end{array}$ & At hospital admission & Yes & Yes & Yes \\
\hline $\begin{array}{l}\text { Wong } \\
(2016)\end{array}$ & QOL & $\begin{array}{l}0.74[0.30 \\
\text { to } 1.18]\end{array}$ & $\begin{array}{l}\text { A complex ACP and } \\
\text { transitional palliative care } \\
\text { programme with } \\
\text { interdisciplinary } \\
\text { communication }\end{array}$ & $\begin{array}{l}\text { Before hospital } \\
\text { discharge }\end{array}$ & Yes & Yes & Yes \\
\hline $\begin{array}{l}\text { Hopp } \\
(2016)\end{array}$ & QOL & $\begin{array}{l}0.00[-0.43 \\
\text { to } 0.43]\end{array}$ & $\begin{array}{l}\text { Single component ACP } \\
\text { intervention: one meeting to } \\
\text { complete an ACP document, } \\
\text { no further patient support }\end{array}$ & During hospital stay & No & No & No \\
\hline $\begin{array}{l}\text { Denvir } \\
(2016)\end{array}$ & QOL & $\begin{array}{l}-0.07[-0.67 \\
\text { to } 0.52]\end{array}$ & $\begin{array}{l}\text { An ACP document is } \\
\text { discussed with patients, } \\
\text { using a multidisciplinary } \\
\text { approach and patient } \\
\text { electronic records }\end{array}$ & $\begin{array}{l}\text { Before hospital } \\
\text { discharge }\end{array}$ & Unclear & Unclear & Yes \\
\hline $\begin{array}{l}\text { Detering } \\
(2010)\end{array}$ & PSEOLC & $\begin{array}{l}0.76[0.52 \\
\text { to } 1.01]\end{array}$ & $\begin{array}{l}\text { A complex respecting } \\
\text { patient choices programme } \\
\text { including ACP, identification } \\
\text { of patient's care preferences } \\
\text { and surrogate decision maker }\end{array}$ & $\begin{array}{l}\text { Before hospital } \\
\text { discharge }\end{array}$ & Yes & Yes & Yes \\
\hline $\begin{array}{l}\text { Engelhardt } \\
(2006)\end{array}$ & PSEOLC & $\begin{array}{l}0.37[0.03 \\
\text { to } 0.70]\end{array}$ & $\begin{array}{l}\text { A complex ACP coordinated } \\
\text { care programme: training } \\
\text { patients to ask questions, } \\
\text { multidisciplinary approach, } \\
\text { increasing patient } \\
\text { self-management }\end{array}$ & Patients were stable & Yes & Yes & Yes \\
\hline $\begin{array}{l}\text { Brumley } \\
(2007)\end{array}$ & PSEOLC & $\begin{array}{l}0.22[-0.00 \\
\text { to } 0.45]\end{array}$ & $\begin{array}{l}\text { An interdisciplinary, } \\
\text { home-based ACP programme } \\
\text { including patients' } \\
\text { self-management }\end{array}$ & Patients were unwell & Unclear & Yes & Yes \\
\hline $\begin{array}{l}\text { Doorenboos } \\
\text { (2016) }\end{array}$ & QEOLC & $\begin{array}{l}0.48[0.03 \\
\text { to } 0.92]\end{array}$ & $\begin{array}{l}\text { Pre-outpatient telephone call to } \\
\text { train patients in ACP } \\
\text { communication and } \\
\text { identifying } \\
\text { end-of-life care wishes; } \\
\text { clinician } \\
\text { informed of patient's wishes } \\
\text { before visit }\end{array}$ & $\begin{array}{l}\text { Hospital outpatient } \\
\text { visit }\end{array}$ & Yes & Yes & Yes \\
\hline $\begin{array}{l}\text { Briggs } \\
(2004)\end{array}$ & QEOLC & $\begin{array}{l}0.76[-0.02 \\
\text { to } 1.55]\end{array}$ & $\begin{array}{l}\text { A single ACP intervention: } \\
\text { facilitator has a single } 2-\mathrm{h} \\
\text { ACP meeting with patient, no } \\
\text { interdisciplinary working and } \\
\text { no F/u }\end{array}$ & $\begin{array}{l}\text { Before elective } \\
\text { admission to hospital }\end{array}$ & Yes & Yes & No \\
\hline
\end{tabular}

ACP advance care planning, F/u follow-up, HF heart failure, PSEOLC patient satisfaction with end-of-life care, QEOLC quality of end-of-life communication, $Q O L$ quality of life

a multidisciplinary team early in the disease trajectory of the patient had a small but positive effect on patient satisfaction with end-of-life care.

Possible causes for the success of the study by Doorenboss et al. ${ }^{55}$ corresponded with factors found in other studies of higher effect sizes: (a) patients were educated by a nurse through a question prompt list before their appointment with the cardiologist, (b) the nurse helped patients identifying and clarifying their care wishes and (c) the clinician was trained in end-of-life communication skills and had an advanced awareness of the patient's care preferences.

Lower effect sizes for the quality of end-of-life communication were reported in the study by Briggs et al. ${ }^{51}$ Possible causes for the comparatively small effect might have been similar to the factors described in the study by Hopp et al. ${ }^{58}$ : ACP was delivered as a single intervention in the context of a 2-h meeting. Interdisciplinary working with other medical specialties was missing, and no follow-up was offered to the patient.

\section{Potential Reasons for Over- and Underestima- tion of Effect}

To evaluate potential overestimation of the impact of ACP on patient outcomes, we carried out subgroup analyses to compare the effect of ACP as a standard intervention versus ACP as part of a complex palliative care programme. Sufficient data were only available for quality of end-of-life communication, and for this outcome, no difference in effect for ACP as a standard intervention compared to ACP as part of a palliative care programme was observed. Heterogeneity was 
Table 3 Causes of Heterogeneity

\begin{tabular}{|c|c|c|c|c|}
\hline$\overline{\overline{\text { Outcome and subgroups }}}$ & Studies & Participants & Effect size SMD, 95\% CI & $\overline{I^{2}}$ \\
\hline Quality of life (QOL) & 7 & 724 & $0.38[0.09$ to 0.66$]$ & $71 \%$ \\
\hline \multicolumn{5}{|l|}{ Patient population } \\
\hline QOL HF patients & 6 & 532 & $0.39[0.04$ to 0.74$]$ & $74 \%$ \\
\hline QOL HF patients + other terminal illnesses & 1 & 192 & $0.28[0.00$ to 0.57$]$ & $\mathrm{n} / \mathrm{a}$ \\
\hline \multicolumn{5}{|l|}{ Study setting } \\
\hline QOL hospital & 3 & 237 & $0.18[-0.07$ to 0.44$]$ & $0 \%$ \\
\hline QOL community & 1 & 192 & $0.28[0.00$ to 0.57$]$ & $\mathrm{n} / \mathrm{a}$ \\
\hline QOL hospital and community & 3 & 295 & $0.58[0.05$ to 1.12$]$ & $77 \%$ \\
\hline \multicolumn{5}{|l|}{ Length of follow-up } \\
\hline QOL F/u to 12 weeks & 7 & 724 & $0.38[0.09$ to 0.66$]$ & $71 \%$ \\
\hline Patient satisfaction with end-of-life care (PSEOLC) & 4 & 1290 & $0.39[0.14$ to 0.64$]$ & $75 \%$ \\
\hline \multicolumn{5}{|l|}{$\begin{array}{l}\text { Patient population } \\
\text { Patientere (PSEULC) }\end{array}$} \\
\hline PSEOLC HF patients + other terminal illnesses & 4 & 1205 & $0.39[0.14$ to 0.64$]$ & $78 \%$ \\
\hline \multicolumn{5}{|l|}{ Study setting } \\
\hline PSEOLC hospital & 2 & 765 & $0.49[-0.03$ to 1.01$]$ & $92 \%$ \\
\hline PSEOLC community & 1 & 297 & $0.22[0.00$ to 0.45$]$ & $\mathrm{n} / \mathrm{a}$ \\
\hline PSEOLC hospital and community 11 & 1 & 143 & $0.37[0.03$ to 0.70$]$ & $\mathrm{n} / \mathrm{a}$ \\
\hline \multicolumn{5}{|l|}{ Length of follow-up } \\
\hline PSEOLC F/u to 12 weeks & 3 & 712 & $0.45[0.11$ to 0.80$]$ & $80 \%$ \\
\hline PSEOLC F/u to 24 weeks & 1 & 493 & $0.23[0.05$ to 0.41$]$ & $\mathrm{n} / \mathrm{a}$ \\
\hline Quality of end-of-life communication (QEOLC) & 4 & 995 & $0.29[0.17$ to 0.42$]$ & $0 \%$ \\
\hline \multicolumn{5}{|l|}{ Patient population } \\
\hline QEOLC HF patients & 1 & 80 & $0.48[0.03$ to 0.92$]$ & $\mathrm{n} / \mathrm{a}$ \\
\hline QEOLC HF patients + other terminal illnesses & 3 & 915 & $0.28[0.15$ to 0.41$]$ & $0 \%$ \\
\hline \multicolumn{5}{|l|}{ Study setting } \\
\hline QEOLC hospital & 4 & 995 & $0.29[0.17$ to 0.42$]$ & $0 \%$ \\
\hline \multicolumn{5}{|l|}{ Length of follow-up } \\
\hline QEOLC F/u to 4 weeks & 3 & 483 & $0.33[0.09$ to 0.57$]$ & $20 \%$ \\
\hline QEOLC F/u to 24 weeks & 1 & 512 & $0.29[0.12$ to 0.47$]$ & $\mathrm{n} / \mathrm{a}$ \\
\hline
\end{tabular}

F/u follow-up, HF heart failure, n/a not applicable, PSEOLC Patient Satisfaction with End-of-Life Care, QEOLC quality of end-of-life communication, QOL quality of life

insignificant and confidence intervals of these two subgroups overlapped substantiating the direction of effect.

The nature of the intervention made it often impossible to blind participants to the intervention resulting in performance and selection biases. These factors may have resulted in a more beneficial effect of ACP compared to standard care since both patients and physicians may believe that the intervention works. These biases are a known issue in assessing complex interventions in palliative care research and need to be considered when interpreting the reliability and statistical significance of effect sizes.

Due to the assumptions to make the conversion from SMDs to ORs, the results are only an approximation. However, the clinical gain seems sufficiently large to justify the effort of engaging with $\mathrm{ACP}$ in heart failure.

\section{CONCLUSIONS AND CLINICAL IMPLICATIONS}

Patients suffering from heart failure have significant palliative care needs. Only the minority of those dying from heart failure receives palliative care and their management remains suboptimal. ACP is widely advocated as a way of addressing these care needs. But until now, the effect of ACP on heart failure has not been systematically assessed.

The evidence from this review indicates that ACP improves the quality of life (SMD, $0.38 ; 95 \%$ CI $[0.09$ to 0.66]), patient satisfaction with end-of-life care (SMD, $0.39 ; 95 \%$ CI $[0.14$ to 0.64$]$ ) and the quality of end-of-life communication (SMD, 0.29; 95\% CI [0.17 to 0.42]) for patients suffering from heart failure. Based on findings from 14 RCTs, we suggest the following considerations to facilitate a better engagement with $\mathrm{ACP}$ in heart failure:

- Introduce ACP at a significant milestone in the patient's disease trajectory, for example, after an unscheduled hospital admission, before hospital discharge or after a deterioration in the patient's health status

- Offer follow-up appointments, preferably two or three meetings or points of contact over a period of time to allow for the clarification and adjustment of care choices

- Be mindful of ACP preferences

- Offer the involvement of family members or of a health care proxy

- Work in a multidisciplinary team and not in isolation within a single medical specialty

Acknowledgements: We acknowledge and thank Nia Roberts, health science librarian, Bodleian Library, University of Oxford, for running the literature data base searches.

Corresponding Author: Markus Schichtel, DPhil; Department of Public Health and Primary Care, Primary Care UnitUniversity of Cambridge, Cambridge, UK (e-mail: ms2591@medschl.cam.ac.uk).

Authors' Contributions The corresponding author, Dr Markus Schichtel, attests that all listed authors meet authorship criteria and that no others meeting the criteria have been omitted. The list of authors including the main author, Markus Schichtel (MS), and the coauthors, Bee Wee (BW), Rafael Perera (RP) and Igho Onakpoya (IO) 
represents all those who can legitimately claim authorship by making a substantial contribution.

MS had the idea for the review; wrote the protocol; extracted, evaluated and analysed the data; and wrote, critically revised and submitted the entire manuscript. BW critically supervised the conduct of the review and revised the entire manuscript. RP critically revised the study protocol, the statistical meta-analyses and publication bias sections as well as the TIDieR analysis of intervention characteristics. IO independently screened papers, extracted data and evaluated risk of bias and study quality according to GRADE and the Cochrane risk of bias assessment tool. All co-authors approved the version to be published.

Availability of Data and Material All data generated or analysed during this study are included in this published article and its supplementary information files.

\section{Compliance with Ethical Standards:}

Ethics Approval and Consent To Participate: Not applicable. This was a review of the literature.

Conflict of Interest: The authors declare that they do not have a conflict of interest.

Open Access This article is distributed under the terms of the Creative Commons Attribution 4.0 International License (http:// creativecommons.org/licenses/by/4.0/), which permits unrestricted use, distribution, and reproduction in any medium, provided you give appropriate credit to the original author(s) and the source, provide a link to the Creative Commons license, and indicate if changes were made.

Publisher's Note: Springer Nature remains neutral with regard to jurisdictional claims in published maps and institutional affiliations.

\section{REFERENCES}

1. LeMond L, Camacho SA, Goodlin SJ. Palliative care and decision making in advanced heart failure. Curr Treat Options Cardiovasc Med. 2015;17(2):359.

2. Taylor CJ, Ryan R, Nichols L, Gale N, Hobbs FDR, Marshall T. Survival following a diagnosis of heart failure in primary care. Fam Pract. 2017;34(2): 161-8.

3. Hupcey JE, Penrod J, Fogg J. Heart failure and palliative care: implications in practice. J Palliat Med. 2009;12(6):531-6.

4. Cubbon RM, Gale CP, Kearney LC, Schechter CB, Brooksby WP, Nolan $\mathbf{J}$, et al. Changing characteristics and mode of death associated with chronic heart failure caused by left ventricular systolic dysfunction: a study across therapeutic eras. Circ Heart Fail. 2011;4(4):396-403.

5. Adler ED, Goldfinger JZ, Kalman J, Park ME, Meier DE. Palliative care in the treatment of advanced heart failure. Circulation. 2009; 120(25):2597-606.

6. British, Heart. Foundation. Coronary disease statistics: heart failure supplement. London: British Heart Foundation; 2016

7. Connolly M, Beattie J, Walker D. End of life care in heart failure: framework for implementation. National End of Life Care Programme. 2010.

8. Johnson M, Green T, Taylor R. Heart failure and hospice care: how to make a difference. London: Hospice UK; 2017.

9. Addington-Hall $\mathbf{J}$, Gibbs JS. Heart failure now on the palliative care agenda. Palliat Med. 2000;14(36): 1-2.

10. Riley JP, Beattie JM. Palliative care in heart failure: facts and numbers. ESC Heart Fail. 2017;4(2):81-7.

11. Gadoud A, Jenkins SMM, Hogg KJ. Palliative care for people with heart failure: Summary of current evidence and future direction. Palliat Med. 2013;27(9):822-8

12. Johnson M, Lehman R. Heart Failure and Palliative Care: a Team Approach. 2nd ed. Oxford. Seattle: Radcliffe; 2015.

13. Mullick A, Martin J, Sallnow L. An introduction to advance care planning in practice. BMJ : Br Med J. 2013;347.

14. Sudore RL, Lum HD, You JJ, Hanson LC, Meier DE, Pantilat SZ, et al. Defining Advance care planning for adults: a consensus definition from a multidisciplinary Delphi panel. J Pain Symptom Manag. 53(5):821-32.e1.
15. Hayhoe B, Howe A. Advance care planning under the Mental Capacity Act 2005 in primary care. Br J Gen Pract. 2011;61(589):e537-e41.

16. Durbin CR, Fish AF, Bachman JA, Smith KV. Systematic review of Educational interventions for improving advance directive completion. J Nurs Scholarsh. 2010;42(3):234-41.

17. Brinkman-Stoppelenburg A, Rietjens JA, Heide AVD. The effects of advance care planning on end-of-life care: a systematic review. Palliat Med. 2014;28(8): 1000-25.

18. Houttekier D, Cohen J, Cools F, Deliens L. Advance care planning for end-of-life care. Cochrane Database Syst Rev. 2012(2).

19. Brown BA. The history of advance directives. A literature review. J Gerontol Nurs. 2003;29(9):4-14.

20. Jezewski MA, Meeker MA, Sessanna L, Finnell DS. The effectiveness of interventions to increase advance directive completion rates. J Aging Health. 2007;19(3):519-36.

21. Patel K, Janssen DJ, Curtis JR. Advance care planning in COPD. Respirology (Carlton, Vic).. 2012;17(1):72-8.

22. Malhotra C, Sim DKL, Jaufeerally F, Vikas NN, Sim GWC, Tan BC, et al. Impact of advance care planning on the care of patients with heart failure: study protocol for a randomized controlled trial. Trials. 2016;17(1):285.

23. Ramsaroop SD, Reid MC, Adelman RD. Completing an advance directive in the primary care setting: what do we need for success? J Am Geriatr Soc. 2007;55(2):277-83.

24. Tamayo-Velazquez MI, Simon-Lorda P, Villegas-Portero R, HiguerasCallejon C, Garcia-Gutierrez JF, Martinez-Pecino F, et al. Interventions to promote the use of advance directives: an overview of systematic reviews. Patient Educ Couns. 2010;80(1):10-20.

25. Hanson LC, Tulsky JA, Danis M. Can clinical interventions change care at the end of life? Ann Intern Med. 1997;126(5):381-8.

26. Houben CH, Spruit MA, Groenen MT, Wouters EF, Janssen DJ. Efficacy of advance care planning: a systematic review and meta-analysis. J Am Med Dir Assoc. 2014;15(7):477-89.

27. Jimenez G, Tan WS, Virk AK, Low CK, Car J, Ho AHY. Overview of systematic reviews of advance care planning: summary of evidence and global lessons. J Pain Symptom Manag.. 2018;56(3):436-59.e25.

28. Shamseer L, Moher D, Clarke M, Ghersi D, Liberati A, Petticrew M, et al. Preferred Reporting Items for Systematic Review and Meta-Analysis Protocols (PRISMA-P) 2015: elaboration and explanation. BMJ : Br Med J. $2015 ; 349$

29. Higgins J, Green S. Cochrane Handbook for Systematic Reviews of Interventions Version 5.1.0 2011. Available from: http://training. cochrane.org/handbook. Accssed 03 Mar 2016

30. Guyatt GH, Oxman AD, Vist GE, Kunz R, Falck-Ytter Y, Alonso-Coello P, et al. GRADE: an emerging consensus on rating quality of evidence and strength of recommendations. BMJ. 2008;336(7650):924-6.

31. Chan A-W, Tetzlaff JM, Gøtzsche PC, Altman DG, Mann H, Berlin JA, et al. SPIRIT 2013 explanation and elaboration: guidance for protocols of clinical trials. BMJ : Br Med J. 2013;346.

32. Raphael C, Briscoe C, Davies J, Ian Whinnett Z, Manisty C, Sutton R, et al. Limitations of the New York Heart Association functional classification system and self-reported walking distances in chronic heart failure. Heart. 2007;93(4):476-82.

33. Stout KK, Broberg CS, Book WM, Cecchin F, Chen JM, Dimopoulos K et al. Chronic Heart Failure in Congenital Heart Disease. A Scientific Statement From the American Heart Association. 2016;133(8):770-801

34. Clifford C, Thomas K, Armstrong-Wilson J. Going for Gold: the Gold Standards Framework programme and accreditation in primary care. End Life J. 2016;7(1).

35. Sepulveda C, Marlin A, Yoshida T, Ullrich A. Palliative care: the World Health Organization's global perspective. J Pain Symptom Manag. 2002;24(2):91-6.

36. Flo E, Husebo BS, Bruusgaard P, Gjerberg E, Thoresen L, Lillemoen L, et al. A review of the implementation and research strategies of advance care planning in nursing homes. BMC Geriatr. 2016;16:24.

37. Bausewein C, Daveson BA, Currow DC, Downing J, Deliens L, Radbruch L, et al. EAPC White paper on outcome measurement in palliative care: improving practice, attaining outcomes and delivering quality services-recommendations from the European Association for Palliative Care (EAPC) Task Force on Outcome Measurement. Palliat Med. 2016;30(1):6-22.

38. Bingham CO, Bartlett SJ, Merkel PA, Mielenz TJ, Pilkonis PA, Edmundson L, et al. Using patient-reported outcomes and PROMIS in research and clinical applications: experiences from the PCORI pilot projects. Qual Life Res. 2016;25(8):2109-16. 
39. Barclay S, Momen N, Case-Upton S, Kuhn I, Smith E. End-of-life care conversations with heart failure patients: a systematic literature review and narrative synthesis. Br J Gen Pract. 2011;61(582):e49-e62.

40. GRADE, Pro, Working, Group. GRADE system Version 3.6.1. 2015 [cited 2017]. Available from: http://www.gradeworkinggroup.org/ index.htm.

41. Cochrane, Informatics, and, Knowledge, Management, Department. RevMan Version 5.3.5. Cochrane Group. Available from: http://tech. cochrane.org/revman/download. Accessed 03 Mar 2016

42. Au DH, Udris EM, Engelberg RA, Diehr PH, Bryson CL, Reinke LF, et al. A randomized trial to improve communication about end-of-life care among patients with COPD. Chest. 2012;141(3):726-35.

43. Haun MW, Estel S, Rucker G, Friederich HC, Villalobos M, Thomas M, et al. Early palliative care for adults with advanced cancer. Cochrane Database Syst Rev 2017;6:CD011129.

44. Cohen, J. Statistical Power Analysis in the Behavioral Sciences. 2nd edition. In: Lawrence Erlbaum Associates I, ed. New Jersey: Hillsdale; 1988.

45. Hoffmann TC, Glasziou PP, Boutron I, Milne R, Perera R, Moher D. Better reporting of interventions: Template for Intervention Description and Replication (TIDieR) checklist and guide. BMJ. 2014;348.

46. Egger M, Smith GD, Phillips AN. Meta-analysis: principles and procedures. BMJ. 1997;315(7121):1533-7.

47. StataCorp, LLC. STATA Version 14. STATA. 2017.

48. Higgins JPT, Altman DG, Gøtzsche PC, Jüni P, Moher D, Oxman AD, et al. The Cochrane Collaboration's tool for assessing risk of bias in randomised trials. BMJ. 2011;343.

49. Aiken LS, Butner J, Lockhart CA, Volk-Craft BE, Hamilton G, Williams FG. Outcome evaluation of a randomized trial of the PhoenixCare intervention: program of case management and coordinated care for the seriously chronically ill. J Palliat Med. 2006;9(1):111-26.

50. Brännström M, Boman $\mathbf{K}$. Effects of person-centred and integrated chronic heart failure and palliative home care. PREFER: a randomized controlled study. Eur J Heart Fail. 2014;16(10):1142-51.

51. Briggs LA, Kirchhoff KT, Hammes BJ, Song M-K, Colvin ER. Patientcentered advance care planning in special patient populations: a pilot study. J Prof Nurs. 2004;20(1):47-58.

52. Brumley R, Enguidanos S, Jamison P, Seitz R, Morgenstern N, Saito $\mathbf{S}$, et al. Increased satisfaction with care and lower costs: results of a randomized trial of in-home palliative care. J Am Geriatr Soc. 2007;55(7):993-1000

53. Denvir M, Cudmore S, Highet G, Robertson S, Donald L, Stephen J, et al. Phase 2 randomised controlled trial and feasibility study of future care planning in patients with advanced heart disease. Sci Rep 2016;6.

54. Detering KM, Hancock AD, Reade MC, Silvester W. The impact of advance care planning on end of life care in elderly patients: randomised controlled trial. BMJ. 2010;340.

55. Doorenbos AZ, Levy WC, Curtis JR, Dougherty CM. An intervention to enhance goals-of-care communication between heart failure patients and heart failure providers. J Pain Symptom Manage. 2016;52(3):353-60.

56. Engelhardt JB, McClive-Reed KP, Toseland RW, Smith TL, Larson DG, Tobin DR. Effects of a program for coordinated care of advanced illness on patients, surrogates, and healthcare costs: a randomized trial. Am J Manag Care. 2006;12(2):93-100.

57. Gade G, Venohr I, Conner D, McGrady K, Beane J, Richardson RH, et al. Impact of an inpatient palliative care team: a randomized control trial. J Palliat Med. 2008;11(2): 180-90.

58. Hopp FP, Zalenski RJ, Waselewsky D, Burn J, Camp J, Welch RD, et al. Results of a hospital-based palliative care intervention for patients with an acute exacerbation of chronic heart failure. J Card Fail. 2016;22(12):1033-6.

59. Rogers JG, Patel CB, Mentz RJ, Granger BB, Steinhauser KE, Fiuzat M, et al. Palliative care in heart failure: the PAL-HF Randomized, Controlled Clinical Trial. J Am Coll Cardiol. 2017;70(3):331-41.

60. Sidebottom AC, Jorgenson A, Richards H, Kirven J, Sillah A. Inpatient palliative care for patients with acute heart failure: outcomes from a randomized trial. J Palliat Med. 2015;18(2):134-42.

61. Wong FKY, Ng AYM, Lee PH, Lam P-t, Ng JSC, Ng NHY, et al. Effects of a transitional palliative care model on patients with end-stage heart failure: a randomised controlled trial. Heart. 2016.

62. Petticrew M, Rehfuess E, Noyes J, Higgins JPT, Mayhew A, Pantoja T, et al. Synthesizing evidence on complex interventions: how metaanalytical, qualitative, and mixed-method approaches can contribute. J Clin Epidemiol. 2013;66(11):1230-43.

63. Lund S, Richardson A, May C. Barriers to advance care planning at the end of life: an explanatory systematic review of implementation studies. PLoS One. 2015;10(2):e0116629.

64. Detering K, Silvester W, Corke C, Milnes S, Fullam R, Lewis V, et al. Teaching general practitioners and doctors-in-training to discuss advance care planning: evaluation of a brief multimodality education programme. BMJ Supportive \&amp; Palliative Care. 2014.

65. Cheang F, Finnegan T, Stewart C, Hession A, Clayton JM. Singlecentre cross-sectional analysis of advance care planning among elderly inpatients. Intern Med J. 2014;44(10):967-74.

66. Stewart S, McMurray JJV. Palliative care for heart failure. BMJ. 2002;325(7370):915.

67. Yancu CN, Farmer DF, Leahman D. Barriers to hospice use and palliative care services use by African American adults. Am J Hosp Palliat Care. 2010;27(4):248-53.

68. Washington KT, Bickel-Swenson D, Stephens N. Barriers to hospice use among African Americans: a systematic review. Health Soc Work. 2008;33(4):267-74

69. Fisher JA, Kalbaugh CA. Altruism in clinical research: coordinators' orientation to their professional roles. Nurs Outlook. 2012;60(3):1438.e1.

70. Reeves S, Pelone F, Harrison R, Goldman J, Zwarenstein $\mathbf{M}$. Interprofessional collaboration to improve professional practice and healthcare outcomes. Cochrane Database Syst Rev 2017(6).

Publisher's Note Springer Nature remains neutral with regard to jurisdictional claims in published maps and institutional affiliations. 